\title{
Cluster analytical approach to Lifestyle characteristics: A population based study in Shiraz, Iran
}

Veda Vakilii', Pardis Shojaei², Zahra Abbasi Shaye², Mojtaba Mousavi Bazaz ${ }^{3}$

${ }^{1}$ MD, Assistant Professor, Department of Community Medicine, Faculty of Medicine, Mashhad University of Medical Sciences, Mashhad, Iran

${ }^{2}$ MD, Resident of Community Medicine, Department of Community Medicine, Faculty of Medicine, Mashhad University of Medical Sciences, Mashhad, Iran

${ }^{3}$ MD, Associate Professor, Department of Community Medicine, Faculty of Medicine, Mashhad University of Medical Sciences, Mashhad, Iran

\section{Type of article: Original}

\begin{abstract}
Introduction: A limited number of risky behaviors cause most morbidity and mortality. The aim of this study was to determine the possible clustering of lifestyle behaviors, including transportation behaviors, diet, physical activity, and smoking in Shiraz, Iran.

Methods: There were 776 representative Shirazi adults who participated in this cross-sectional study. The questionnaires were completed via person-to-person interviews. The datasets were searched for any clustering patterns. Cluster analysis was used for statistical analysis, and the data were analyzed using SPSS version 11.5.

Results: Three distinct clusters were identified. Cluster 1 was named "Healthy," and it included non-smokers, safe drivers, appropriate or acceptable fruit, vegetable, and fast-food consumers, and physically-active people. Cluster 2, "Moderately Healthy," was relatively risky drivers who had appropriate behaviors on the rest of the health-related behaviors. Cluster 3, "Unhealthy," was smokers, risky drivers, inappropriate or unacceptable fruit, vegetable \& fast-food consumers, and a sedentary lifestyle.

Conclusions: It was obvious that health-related behaviors were clustered together and unhealthy behaviors were not established in isolation.

Keywords: Cluster analysis, Lifestyle, Transportation behaviors, Iran
\end{abstract}

\section{Introduction}

The patterns of deaths and diseases have changed during the twenty-first century, shifting from communicable and infectious diseases to lifestyle-related diseases. Currently, non-communicable diseases comprise $43 \%$ of the illness load all over the world, and this percentage is expected to increase to $60 \%$ by 2020 (1). While suffering from malnutrition and low weight are among the causes of children's deaths in the world's poor countries, in more developed areas, such as the United States and Europe, many people die of obesity and its related risks. Iran must deal with a double burden of diseases, i.e., communicable and non-communicable diseases. However, the highest rate of Disability Adjusted Life Years (DALY) in Iran is related to motor-vehicle accidents, heart disease, and cancer (2). The findings of various research efforts have indicated that half of all deaths may occur due to a limited number of behaviors and preventable measures. The use of tobacco and cigarettes, improper diet, insufficient physical activities, alcohol, infectious factors, toxins and pollutants, motor vehicle deaths, risky sexual behaviors, and drug abuse are the major causes of death (3). The use of fatty and salt-containing foods is associated with an increase in serum cholesterol and high blood pressure levels, resulting in increased risk for cardiovascular diseases. In contrast, eating fruit and vegetables can prevent many cardiovascular diseases and some types of cancers. It is estimated that low consumption of fruit and vegetables in the daily diet may lead to about 2.7 million deaths annually. It also has been observed that the lack of physical activities is correlated with the incidence of many

\section{Corresponding author:}

Associate Professor Dr. Mojtaba Mousavi Bazaz, Department Of Community Medicine, Faculty of Medicine, Mashhad University of Medical Sciences, Mashhad, Iran. Tel: 98.5138002386, E-mail: MousaviM@mums.ac.ir Received: October 02, 2015, Accepted: March 04, 2016, Published: May 2016 iThenticate screening: March 04, 2016, English editing: April 02, 2016, Quality control: May 05, 2016 (C) 2016 The Authors. This is an open access article under the terms of the Creative Commons Attribution-NonCommercialNoDerivs License, which permits use and distribution in any medium, provided the original work is properly cited, the use is non-commercial and no modifications or adaptations are made. 
cancers, diabetes, and cardiovascular diseases (4). In 2000, almost a million deaths and over 50 million injuries occurred due to unintentional accidents worldwide, $90 \%$ of which occurred in low-to-middle income countries (5). Fewer accidents would occur if more attention were paid to high risk behaviors, such as not fastening seatbelts, not observing speed limits, and not adjusting the driving speed to better match road conditions (6). Various healthrelated behaviors may together, and it has been proven that the combination of two or more lifestyle risk factors increases the likelihood of many serious chronic diseases (7-9). The high priority of establishing more effective preventive strategies and the limited number of research efforts that consider people's lifestyle characteristics in combination necessitate conducting such studies to better understand the characteristics of the target population and to develop and implement more effective interventional strategies. Using cluster analysis, we searched for probable patterns in our data by grouping the observations into clusters. Cluster analysis or clustering is the task of grouping a set of characteristics in such a way that characteristics in the same group (called cluster) are more similar (in some sense or another) to each other than to those in other groups (clusters). It is a main task of exploratory data mining, and a common technique for statistical data analysis used in many fields (10).To the best of our knowledge, this was the first study in Iran with the aim of determining whether there are any specific subgroups or clusters due to lifestyle and health behaviors as well as demographic characteristics. The promise was to find the natural groupings and show how behaviors cluster together so that the healthcare providers and policy makers can design more effective interventional strategies within the community.

\section{Material and Methods}

\subsection{Study setting, sampling, and eligibility criteria}

This study was conducted in Shiraz, Iran in 2010. Shiraz is the largest city in the southern half of Iran, and it is the capital of Fars Province, which as a population of about 1,400,000 people. In a cross-sectional design, we assessed a representative sample of the adults in Shirazi and searched for patterns of health-related behaviors in our data by grouping the observations into clusters. The participants were citizens of Shiraz who were 18 and older. People who resided in dormitories and institutions, in extremely remote locations, or were nationals from other countries were excluded from this study. People with dementia and psychosis also were excluded. Applying the multistage cluster sampling method, we divided Shiraz into nine neighborhoods, and five of these neighborhoods were selected randomly at the first step. Then, the selected neighborhoods were divided into blocks, and $50 \%$ of the blocks were chosen randomly from within each selected neighborhood. Finally, the houses were listed within each selected block, and $50 \%$ of these houses were selected through a systematic sampling method. As a result, 776 adults in Shirazi participated in the study. (The sample size was calculated based on $\alpha=5 \%, p=23.8 \%, d=3 \%$.)

\subsection{Instrument development, validity, and reliability}

After an extensive literature search and after obtaining experts' opinions, a questionnaire was designed based on four health-related behaviors, i.e., the use of tobacco products, transportation behaviors, diet, and fitness activities. In the first step, a pilot study was performed on 100 residents of Shirazi who met the inclusion criteria in order to establish face validity of the questionnaire. The simplicity, relevance, and clarity of each question were discussed. During the pilot study, the interviewers discussed the clarity of each question with the participants, and questions were omitted or revised if more than half of the pilot participants thought the questions were unclear. In fact, no questions were omitted, but a few questions were revised to increase their clarity. Some experts on health-related behaviors reviewed the questionnaire, and their comments contributed to the improvement of the validity of the questions. Repeatability of the questionnaire was examined by test-retest reliability on the same questionnaire and under the same conditions, and Cronbach's alpha $(\alpha=0.78)$ was obtained. Our well-validated questionnaires were completed via face-to-face interviews.

\subsection{Questionnaire}

The questionnaire covered the following sets of variables:

1) Demographic characteristics: Age, gender, weight, height, marital status (married, single), occupation (housewife/jobless, non-manual, manual, student), educational level classified as $0-5$ years (i.e., primary school), 512 years (i.e., high school), 12-16 years (graduate studies), more than 16 years (post graduate studies), and residential place (categorized into five codes). Note that the characteristics of weight and height were measured by researcher with the same instrument. Residential place is an indicator for socioeconomic status (SES) in this study, and code 1 implied low SES; code 2 implied low-to-moderate SES; code 3 implied moderate-to-high SES; code 4 implied high SES; and code 5 implied very high SES.

2) The habit of using tobacco products: Regular cigarette or hookah smokers were identified. 
3) Transportation behavior: Data on self-reported adherence to fastening the seatbelt and obeying the speed limits among eligible participants (drivers were asked about obeying the speed limit) at all times were obtained.

4) Diet: The consumption of fruit and vegetables consumption and the frequency of consuming fast foods were mentioned. According to standard recommendations, the consumption of at least 2 units of fruit and 3 units of vegetables per day was considered as appropriate behavior (11). Fast food consumption of once a month or less was considered acceptable.

5) Fitness activities: Defined as activities leading to elevation of the heart rate beyond the normal rhythm. Healthy physical activity was considered to be 20 min of exercise three or more times per week (12).

\subsection{Data collection and research ethics}

A two-hour training course was provided for the interviewers. We tried to minimize potential interviewer bias by establishing the same structured interview schedule and giving comprehensive training to the interviewers. To avoid halo effects, some related statements were reversely scaled. Completion of the survey implied consent. The Medical Ethics Committee of Shiraz University of Medical Science approved the initiation of the project. The interviewer described to the participants that their help was voluntary, but very important, and said "if you feel any discomfort in answering the questions, you have the right to stop participating at any time and you can refuse to answer any question."

\subsection{Data analyses}

Two-step cluster analysis was used to identify the number of different lifestyle clusters and the characteristics of each cluster. This method is best suited for large sample sizes, ideally more than 200 . The categorical data and the continuous data can be used in this analytical procedure. The procedure searches for patterns in a dataset by automatically grouping the observations into clusters and determining the optimal grouping in a specific population. As a matter of fact, characteristics within each cluster were similar, but the clusters were different from each other. We used the two-step cluster analysis based on four health-related behaviors, including Tobacco products use habit, Transportation behaviors, Diet, and Fitness activities. In the next step, the chi-squared test, t-test, and ANOVA were administered to determine the statistically-significant differences between clusters according to demographic and health-related behaviors. P-values less than 0.05 were considered as significant. All statistical analyses were performed by SPSS version 11.5 (SPSS, Inc., Chicago, Illinois, USA).

\section{Results}

Socio-demographic characteristics of the study population by gender are reported in Table 1 . The sample consisted of 404 males and 372 females. The mean ( \pm SD) age of the study sample was 39.9 ( \pm 1.5$)$. The sample predominantly consisted of married people $(68.2 \%)$, and $35.6 \%$ had an academic education. The mean Body Mass Index (BMI) of the study sample was $24.4 \pm 4.1$. Table 2 depicts the health-related behaviors of the study population by gender. Our findings supported the significant difference of smoking between the genders. The proportion of smokers was higher among men, i.e., 119 (29.5\%). However, men did better in fastening the seatbelt at all times $(55.7 \%)$. No gender differences emerged for complete adherence to obeying the speed limit. Although females had better adherence to diet recommendations, only $107(28.8 \%)$ of them reported eating the recommended amount of at least two servings of fruit and three units of vegetables per day. But 267 (71.8\%) of the females reported acceptable fast food consumption habits. No gender differences were identified for appropriate fitness activity, although males did slightly more fitness activities. Three distinct clusters were identified based upon four health-related behaviors (Table 3). Cluster 1 "Healthy" (low risk) was shaped by the lack of smoking and relatively high proportion of complete adherence to fastening the seatbelt and obeying the speed limit. Relatively appropriate fruit and vegetable consumption, as well as acceptable fast-food consumption and appropriate fitness activity, also were the characteristics of this cluster. Cluster 2 "Moderately Healthy" (moderate risk) was shaped by the lack of smoking and relatively high proportion of complete adherence to fastening the seatbelt, appropriate fruit and vegetable consumption, acceptable fast-food consumption, and appropriate fitness activity. However, the lack of complete adherence to obeying the speed limit was another characteristic that shaped this cluster. Cluster 3 "Unhealthy" (high risk) consisted of smokers, risky drivers, inappropriate or unacceptable fruit, vegetable, and fast-food consumers as well as sedentary lifestyles. The pattern of cluster membership differed across gender, age, marital status as well as education, occupation, and living area. There was a significant association between clusters 2 and 3 with gender, with a higher percentage of females in cluster 2 and men in cluster 3. Age and marital status were associated with clusters 2 and 3. A greater percentage of married people shaped cluster 3 in comparison with clusters 1 and 2 . There was a significant difference between cluster 2 and the other clusters according to the educational level. Post-graduate studies were less prevalent among cluster 2 members. Occupation correlated with clusters 2 and 3. 
Table 1. Socio-demographic characteristics of the study population by gender

\begin{tabular}{|c|c|c|c|c|}
\hline \multicolumn{2}{|l|}{ Variables } & Male $[\mathrm{n}=404(52.1 \%)]$ & Female $[\mathrm{n}=372(47.9 \%)]$ & p-value \\
\hline \multicolumn{2}{|l|}{ Age $($ mean \pm SD) } & $40.2 \pm 16.1$ & $39.7 \pm 14.2$ & 0.628 \\
\hline \multicolumn{2}{|l|}{ BMI } & $24.3 \pm 4.1$ & $24.4 \pm 4.2$ & 0.598 \\
\hline \multirow[t]{2}{*}{ Marital status (\%) } & Single & $138(34.2)$ & $109(29.3)$ & \multirow[t]{2}{*}{0.147} \\
\hline & Married & $266(65.8)$ & $263(70.7)$ & \\
\hline \multirow[t]{4}{*}{ Education [n (\%)] } & $\leq 5$ years & $59(14.6)$ & $94(25.3)$ & \multirow[t]{4}{*}{$<0.001$} \\
\hline & $6-12$ years & $178(44.1)$ & $169(45.4)$ & \\
\hline & $13-16$ years & $142(35.1)$ & $99(26.6)$ & \\
\hline & $\geq 17$ years & $25(6.2)$ & $10(2.7)$ & \\
\hline \multirow[t]{4}{*}{ Occupation (\%) } & Jobless/ housewife & $63(15.6)$ & $259(69.6)$ & \multirow[t]{4}{*}{$<0.001$} \\
\hline & Non-manual & $102(25.2)$ & $41(11.0)$ & \\
\hline & Manual & $192(47.5)$ & $32(8.6)$ & \\
\hline & Student & $47(11.6)$ & $40(10.8)$ & \\
\hline \multirow[t]{5}{*}{ Living location (SES) (\%) } & Low & $51(12.6)$ & $44(11.8)$ & \multirow[t]{5}{*}{0.803} \\
\hline & Low to moderate & $93(23.0)$ & $96(25.8)$ & \\
\hline & Moderate to high & $157(38.9)$ & $146(39.2)$ & \\
\hline & High & $73(18.1)$ & $57(15.3)$ & \\
\hline & Very high & $30(7.4)$ & $29(7.8)$ & \\
\hline
\end{tabular}

Table 2. Health-related behaviors of the study population by gender

\begin{tabular}{|c|c|c|c|c|c|}
\hline \multicolumn{2}{|l|}{ Variable } & $\begin{array}{l}\text { Male } \\
{[\mathrm{n}=404} \\
(52.1 \%)]\end{array}$ & $\begin{array}{l}\text { Female } \\
{[\mathrm{n}=372} \\
(47.9 \%)]\end{array}$ & $\begin{array}{l}\mathrm{p}- \\
\text { value }\end{array}$ & $\begin{array}{l}\text { Total } \\
(\mathrm{n}=776)\end{array}$ \\
\hline \multicolumn{2}{|l|}{ Smoker (\%) } & $119(29.5)$ & $45(12.1)$ & $<0.001$ & $164(21.1)$ \\
\hline \multirow{2}{*}{$\begin{array}{l}\text { Transportation } \\
\text { behaviors (\%) }\end{array}$} & Complete adherence to fasten seatbelt & $225(55.7)$ & $169(45.4)$ & 0.004 & $394(50.8)$ \\
\hline & Complete adherence to obey speed limit & $170(42.1)$ & $146(39.2)$ & 0.422 & $316(40.7)$ \\
\hline \multirow[t]{2}{*}{ Diet $(\%)$} & Appropriate fruit \& vegetable consumption & $84(20.8)$ & $107(28.8)$ & 0.010 & $585(75.4)$ \\
\hline & Acceptable fast-food consumption & $262(64.9)$ & $267(71.8)$ & 0.039 & $529(68.2)$ \\
\hline \multicolumn{2}{|c|}{ Appropriate fitness activity (\%) } & $133(32.9)$ & $110(29.6)$ & 0.315 & $533(68.7)$ \\
\hline
\end{tabular}

Table 3. Health-related behaviors of three clusters

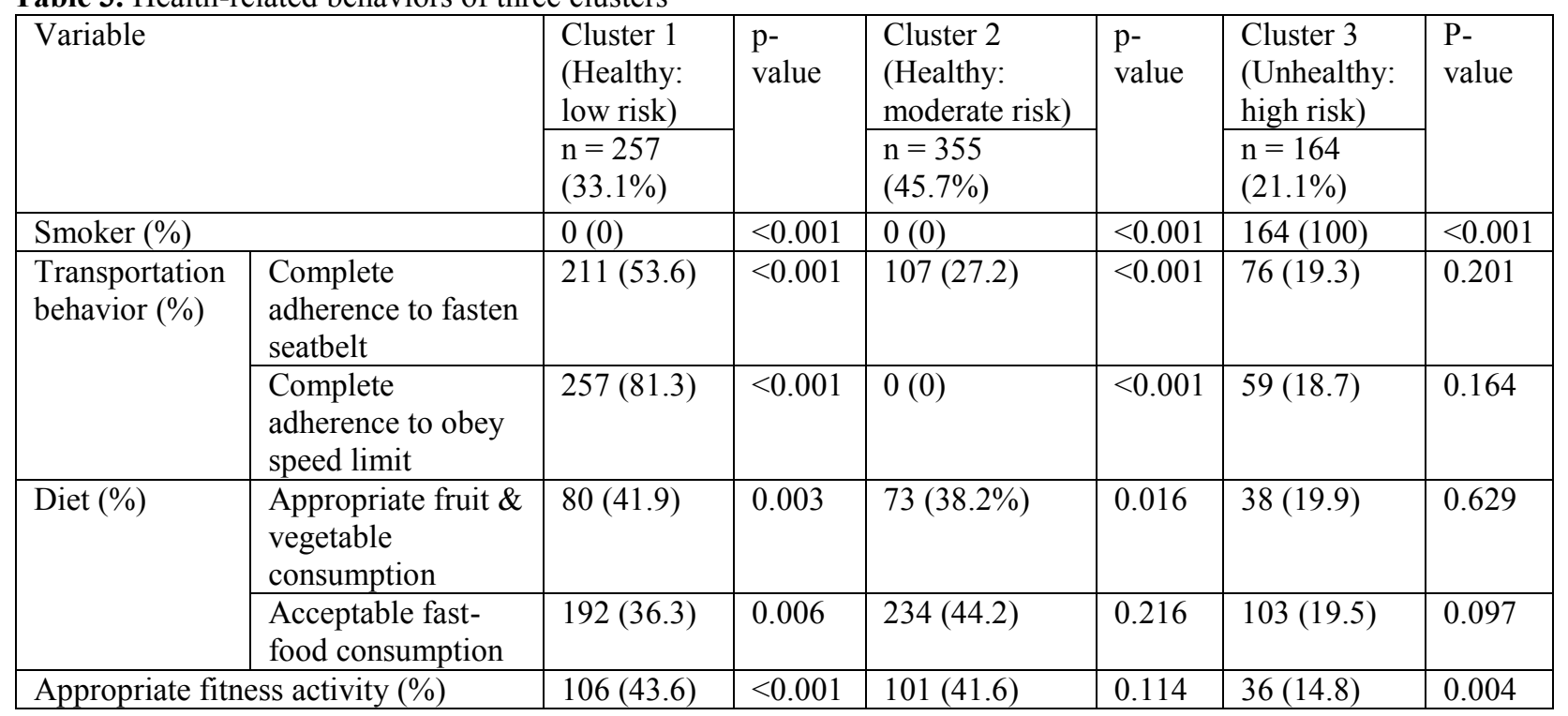

Half of the participants in cluster 3 had manual jobs. Living area correlated with membership in all the 3 clusters (Table 4). The results of the chi-squared test revealed significant differences between the clusters and the healthrelated behaviors. There was a significant difference between cluster 3 with clusters 1 and 2 on smoking. All of the 
people in cluster 3 were smokers despite the fact that there were no smokers in clusters 1 and 2 . There was a significant difference between cluster 1 with clusters 2 and 3 on complete adherence to fastening the seatbelt. A relatively higher percentage of people in cluster 1 reported fastening the seatbelt at all times. There were significant differences between cluster 1 and 2 in comparison with cluster 3 on complete adherence to obeying the speed limit. Our findings did not support the significant differences between complete adherence to obeying the speed limit and cluster 3. A relatively high percentage of people in cluster 1 obeyed the speed limit at all times, and, amazingly, no one reported complete adherence to obeying the speed limit in cluster 2 . There were significant differences between clusters 1 and 2 and appropriate fruit and vegetable consumption. A relatively higher percentage of people in clusters 1 and 2 in comparison to cluster 3 reported more positive behaviors on fruit and vegetable intakes. There were significant differences between cluster 1 in comparison to clusters 2 and 3 on acceptable fast-food consumption. A relatively lower percentage of people in cluster 1 reported acceptable fast-food consumption. There were significant differences between cluster 1 in comparison to clusters 2 and 3 on appropriate fitness activity. The participants in cluster 1 demonstrated more positive behaviors regarding fitness activity (Table 3 ).

Table 4. Demographic characteristics of three clusters

\begin{tabular}{|c|c|c|c|c|c|c|c|}
\hline \multirow{2}{*}{\multicolumn{2}{|c|}{ Variable }} & Cluster 1 & $\mathrm{p}$ & Cluster 2 & $\mathrm{p}$ & Cluster 3 & $\mathrm{p}$ \\
\hline & & $\begin{array}{l}n=257 \\
(33.1 \%)\end{array}$ & & $\begin{array}{l}\mathrm{n}=355 \\
(45.7 \%)\end{array}$ & & $\begin{array}{l}\mathrm{n}=164 \\
(21.1 \%)\end{array}$ & \\
\hline \multirow[t]{2}{*}{ Gender } & Male & $129(50.2)$ & \multirow[t]{2}{*}{0.464} & $156(43.9)$ & \multirow[t]{2}{*}{$<0.001$} & $119(72.6)$ & \multirow[t]{2}{*}{$<0.001$} \\
\hline & Female & $128(49.8)$ & & $199(56.1)$ & & $45(27.4)$ & \\
\hline \multicolumn{2}{|l|}{ Age $($ mean \pm SD $)$} & $41.0 \pm 15.5$ & 0.189 & $37.9 \pm 15.4$ & 0.001 & $42.7 \pm 13.7$ & 0.008 \\
\hline \multicolumn{2}{|l|}{ BMI (mean \pm SD) } & $24.1 \pm 3.8$ & 0.265 & $24.5 \pm 4.2$ & 0.248 & $24.3 \pm 4.6$ & 0.901 \\
\hline \multirow[t]{2}{*}{ Marital status (\%) } & Single & $79(30.7)$ & \multirow[t]{2}{*}{0.646} & $129(36.3)$ & \multirow[t]{2}{*}{0.013} & $39(23.8)$ & \multirow[t]{2}{*}{0.013} \\
\hline & Married & $178(69.3)$ & & $226(63.7)$ & & $125(76.2)$ & \\
\hline \multirow[t]{4}{*}{ Education (\%) } & $\leq 5$ years & $43(16.7)$ & \multirow[t]{4}{*}{0.135} & $73(20.6)$ & \multirow[t]{4}{*}{0.015} & $37(22.6)$ & \multirow[t]{4}{*}{0.115} \\
\hline & $6-12$ years & $117(45.5)$ & & $152(42.8)$ & & $78(47.6)$ & \\
\hline & 13-16 years & $80(31.1)$ & & $122(34.4)$ & & $39(23.8)$ & \\
\hline & $\geq 17$ years & $17(6.6)$ & & $8(2.3)$ & & $10(6.1)$ & \\
\hline \multirow[t]{4}{*}{ Occupation (\%) } & $\begin{array}{l}\text { Jobless/ } \\
\text { housewife }\end{array}$ & $115(44.7)$ & \multirow[t]{4}{*}{0.083} & $162(45.6)$ & \multirow[t]{4}{*}{$<0.001$} & $45(27.4)$ & \multirow[t]{4}{*}{$<0.001$} \\
\hline & Non-manual & $55(21.4)$ & & $60(16.9)$ & & $28(17.1)$ & \\
\hline & Manual & $64(24.9)$ & & $78(22.0)$ & & $82(50.0)$ & \\
\hline & Student & $23(8.9)$ & & $55(15.5)$ & & $9(5.5)$ & \\
\hline \multirow{5}{*}{$\begin{array}{l}\text { Living location } \\
\text { (SES) }(\%)\end{array}$} & Low & $23(8.9)$ & \multirow[t]{5}{*}{$<0.001$} & $41(11.5)$ & \multirow[t]{5}{*}{$<0.001$} & $31(18.9)$ & 0.001 \\
\hline & $\begin{array}{l}\text { Low to } \\
\text { moderate }\end{array}$ & $69(26.8)$ & & $77(21.7)$ & & $43(26.2)$ & 0.001 \\
\hline & $\begin{array}{l}\text { Moderate to } \\
\text { high }\end{array}$ & $122(47.5)$ & & $135(38.0)$ & & $46(28.0)$ & 0.001 \\
\hline & High & $16(6.2)$ & & $89(25.1)$ & & $25(15.2)$ & 0.001 \\
\hline & Very high & $27(10.5)$ & & $13(3.7)$ & & $19(11.6)$ & 0.001 \\
\hline
\end{tabular}

\section{Discussion}

Cardiovascular diseases, motor vehicle accidents, and cancers are the leading causes of morbidity and mortality In Iran (2). Modifying lifestyle factors, such as smoking $(13,14)$, obesity $(15,16)$, adherence to traffic laws and regulations $(6)$, and physical activity $(17,18)$ are the widely-accepted behaviors associated with an increased risk of such diseases and conditions. Identification of target population with risky behaviors to develop more specific and effective preventive strategies is of interest. To the best of our knowledge, this is the first study to determine the clustering of Iranian transportation behavior in conjunction with the rest of important lifestyle characteristics including diet, physical activity and smoking within a representative sample of Iranian (Shirazi) adults. Three distinct clusters were identified based upon four health related behaviors (Table 3). Cluster 1 "Healthy" (low risk) was non-smokers, safe drivers, appropriate or acceptable fruit, vegetable and fast-food consumers, and physically active people. Cluster 2 "Moderately Healthy"' (moderate risk) was relatively risky drivers who had appropriate behaviors on the rest of health-related behaviors. Cluster 3 "Unhealthy"(high risk) was smokers, risky drivers, inappropriate or unacceptable fruit, vegetable and fast-food consumers as well as sedentary lifestyle. Nearly, a fourth of the sample was characterized as having an unhealthy lifestyle (cluster 3). Furthermore, a higher percentage 
of men and married people were in this cluster. Half of the participants in cluster 3 had manual jobs. It was suggested that male gender, non-manual job, and marital status are at higher risks of unhealthy lifestyle. Such findings among men were consistent with other studies $(19,20)$. We assumed that married people choose less healthy lifestyle as a result of higher levels of perceived emotional stress due to higher responsibilities and more extensive familial and social roles. However, this idea should be confirmed by further studies in future. Nearly half of the sample reported relatively healthy lifestyles but lacked adherence to obeying the speed limits, which was a significant finding in this cluster. Post-graduate people were fewer among cluster 2 members than the other two clusters. It was found that even when Shirazi people had a relatively better adherence to a healthy lifestyle, their behaviors regarding traffic laws and regulations were completely unacceptable. Many surveys have depicted significant differences between reported and observed driving behaviors, such as safety belt use; however, the magnitude of the over-reporting is still controversial (21). Keeping in mind the high burden of traffic road injuries in Iran, this emphasizes the urgent need for educational and motivational strategies to improve transportation behavior and adherence to traffic laws and regulations in Iran.

Overall, this study depicts a worrying picture of health-related behaviors of Iranian citizens. Near a quarter of them were smokers and about a third of them had unacceptable diet and physical activities, and only about half of them reported complete adherence to fastening the seatbelt and obeying speed limits. These findings revealed that healthrelated behaviors should not be considered in isolation from each other (9). It is ideal to keep in mind the limitations of this study, in order to interpret the findings rationally. We attempted to minimize the potential interviewers and recall bias by employing expert interviewers and giving them extensive training as well as using the same interview schedule; nonetheless, a continuum of recall and interviewer's bias were unavoidable. Social desirability bias arising from face-to-face interview may lead to over-/under-reporting and subsequently make it difficult to estimate the accurate health-related behavior, and this also may have affected the accuracy of the results of this study. Objective measurement of behavior, such as camera speed control, application of pedometer to measure physical activities, and others, could have improved the validity of the findings. Ultimately, we had limitations in assessing all the potential factors related to lower adherence to healthy lifestyle, and it may lead to a lower power of this study. This study introduced important practical information to policy makers to design and tailor preventive interventions that suit the target population. It was obvious that health-related behaviors were clustered together and that unhealthy behaviors were not established in isolation. Such studies warrant replication in other settings and populations within developing countries.

\section{Conclusions}

Three distinct clusters were identified. Cluster 1, named "Healthy" was non-smokers, safe drivers, appropriate or acceptable fruit, vegetable and fast-food consumers, and physically active people. Cluster 2, "Moderately Healthy," was relatively risky drivers who had appropriate behaviors on the rest of the health-related behaviors. Cluster 3 , "Unhealthy," was smokers, risky drivers, inappropriate or unacceptable fruit, vegetable and fast-food consumers as well as sedentary lifestyle. It was obvious that health-related behaviors were clustered together and unhealthy behaviors were not established in isolation. These findings are helpful for healthcare providers and policy makers to design more efficient interventional strategies within the community.

\section{Acknowledgments:}

This study was supported by Shiraz University of Medical Sciences (Shiraz, Iran). We appreciate the efforts of all people involved in the project for recruiting participants and collecting the data. We thank all of the participants for their cooperation and for providing personal information.

\section{Conflict of Interest:}

There is no conflict of interest to be declared.

\section{Authors' contributions:}

All authors contributed to this project and article equally. All authors read and approved the final manuscript.

\section{References:}

1) Asgari F, Aghajani H, Haghazali M, Heidarian H. Non-Communicable Diseases Risk Factors Surveillance in Iran. Iranian J Publ Health. 2009; 38(1): 119-22.

2) Jafari N, Abolhassani F, Naghavi M, Pourmalek F, MoradiLakeh M, Kazemeini H, et al. National Burden of Disease and Study in Iran. Iranian J Publ Health. 2009; 38: 71-3. 
3) Hendricks KM, Herbold N, Fung T. Diet and other lifestyle behaviours in young college women. Nutrition Research. 2004; 24: 981-91. doi:10.1016/j.nutres.2004.09.004.

4) Schneider M, Norman R, Steyn N, Bradshaw D. South African Comparative Risk Assessment Collaborating Group. Estimating the burden of disease attributable to low fruit and vegetable intake in South Africa in 2000. S Afr Med J. 2007; 97(8): 717-23. PMID: 17952229.

5) Hyder AA, Amach OH, Garg N, Labinjo MT. Estimating the burden of road traffic injuries among children and adolescents in urban South Asia. Health Policy. 2006; 77(2): 129-39. doi: 10.1016/j.healthpol.2005.07.008, PMID: 16112772.

6) De Lapparent M. Willingness to use safety belts and levels of injury in car accidents. Accid Anal Prev. 2008; 40(3): 1023-32. doi: 10.1016/j.aap.2007.11.005, PMID: 18460371.

7) Weiss K, Wertheim EH. An evaluation of a prevention program for disordered eating in adolescent girls: examining responses of high and low-risk girls. Eat Disord. 2005; 13(2): 143-56. doi: 10.1080/10640260590918946, PMID: 16864338.

8) Larson NI, Story M, Perry CL, Neumark-Sztainer D, Hannan PJ. Are diet and physical activity patterns related to cigarette smoking in adolescents? Findings from project EAT. Prev Chronic Dis. 2007; 4(3): 51. PMCID: PMC1955390.

9) Dodd LJ, Al-Nakeeb Y, Nevill A, Forshaw MJ. Lifestyle risk factors of students: a cluster analytical approach. Prev Med. 2010; 51(1): 73-7. doi: 10.1016/j.ypmed.2010.04.005. doi: 10.1016/j.ypmed.2010.04.005, PMID: 20385163.

10) Bjertnaes O, Skudal KE, Iversen HH. Classification of patients based on their evaluation of hospital outcomes: cluster analysis following a national survey in Norway. BMC Health Serv Res. 2013; 13(1): 73. doi: 10.1186/1472-6963-13-73.

11) Casagrande SS, Wang Y, Anderson C, Gary TL. Have Americans increased their fruit and vegetable intake? The trends between 1988 and 2002. Am J Prev Med, 2007; 32(4): 257-63. doi: 10.1016/j.amepre.2006.12.002, PMID: 17383556.

12) Lang RS, Hensrud DD. Clinical preventive medicine. 2nd ed. Chicago, USA: AMA Press, 2004: 138.

13) Doll R, Peto R, Boreham J, Sutherland I. Mortality in relation to smoking: 50 years' observations on male British doctors. BMJ. 2004; 328(7455): 1519. doi: 10.1136/bmj.38142.554479.AE, PMID: 15213107 , PMCID: PMC437139.

14) Noale M, Minicuci N, Bardage C, Gindin J, Nikula S, Pluijm S, et al. Predictors of mortality: an international comparison of socio-demographic and health characteristics from six longitudinal studies on aging: the CLESA project. Exp Gerontol. 2005; 40(1-2): 89-99. doi: 10.1016/j.exger.2004.09.003, PMID: 15732192.

15) Hozawa A, Okamura T, Oki I, Murakami Y, Kadowaki T, Nakamura K, et al. Relationship between BMI and all-cause mortality in Japan: NIPPON DATA80. Obesity (Silver Spring). 2008; 16(7): 1714-7. doi: 10.1038/oby.2008.237, PMID: 18421264.

16) Tsugane S, Sasaki S, Tsubono Y. Under- and overweight impact on mortality among middle-aged Japanese men and women: a 10-y follow-up of JPHC study cohort I. Int J Obes Relat Metab Disord. 2002; 26(4): 529-37. doi: 10.1038/sj.ijo.0801961, PMID: 12075580.

17) Fujita K, Takahashi H, Miura C, Ohkubo T, Sato Y, Ugajin T, et al. Walking and mortality in Japan: the Miyagi cohort Study. J Epidemiol. 2004; 14: S26-32. doi: 10.2188/jea.14.S26, PMID: 15143875.

18) Hamer M, Chida Y. Walking and primary prevention: a meta-analysis of prospective cohort studies. $\mathrm{Br} \mathrm{J}$ Sports Med. 2008; 42(4): 238-43. doi: 10.1136/bjsm.2007.039974, PMID: 18048441.

19) King DE, Mainous AG 3rd, Carnemolla M, Everett CJ. Adherence to healthy lifestyle habits in US adults, 1988-2006. Am J Med. 2009; 122(6): 528-34. doi: 10.1016/j.amjmed.2008.11.013, PMID: 19486715.

20) von Bothmer MI, Fridlund B. Gender differences in health habits and in motivation for a healthy lifestyle among Swedish university students. Nurs Health Sci. 2005; 7(2): 107-18. doi: 10.1111/j.14422018.2005.00227.x, PMID: 15877687.

21) Parada MA, Cohn LD, Gonzalez E, Byrd T, Cortes M. The validity of self-reported seatbelt use: Hispanic and non-Hispanic drivers in El Paso. Accid Anal Prev. 2001; 33(1): 139-43. doi: 10.1016/S00014575(00)00012-9. 